\title{
Vitamin C: is it time to re-evaluate its role in health and disease?
}

\author{
Ryszard Rutkowski ${ }^{1}$, Krzysztof Rutkowski², Joanna Rutkowska-Talipska³, Paweł Sowa ${ }^{4}$, Stanisław Sulkowski ${ }^{5}$
}

\author{
1Department of Respiratory Diagnostic and Bronchoscopy, Medical University, Bialystok, Poland \\ Head: Prof. Zenon Siergiejko MD, PhD \\ 2Department of Allergy, Cambridge University Hospital, Cambridge, United Kingdom \\ Head: Dr P.W. Ewan FRCP, FRCPath \\ ${ }^{3}$ Department of Rehabilitation, Medical University, Bialystok, Poland \\ Head: Prof. Anna Kuryliszyn-Moskal MD, PhD \\ ${ }^{4}$ Faculty of Public Health, Stanislaw Staszic College of Public Administration, Bialystok, Poland \\ Head: Prof. Andrzej Szpak MD, PhD \\ ${ }^{5}$ Department of Pathomorphology, Medical University, Bialystok, Poland \\ Head: Prof. Andrzej Kemona MD, PhD
}

Postep Derm Alergol 2012; XXIX, 6: 456-460

DOI: 10.5114/pdia.2012.32394

\begin{abstract}
Vitamin C (VC; ascorbic acid, AA) is synthesised from glucose in the liver of most mammals, but not in humans. Synthetic AA supplementation is often necessary to prevent vitamin C deficiency. Intracellularly AA is reversibly oxidized to an ascorbic radical which converts into dehydroascorbic acid (DHA). Ascorbic acid crosses cell membranes with SVCT1, SVCT2 or GLUT1, GLUT3 and GLUT4 transporters. Recommended daily allowance for VC is around $75 \mathrm{mg} / \mathrm{day}$ for women and $90 \mathrm{mg} /$ day for men. This seems to be too low in relation to real human body needs and does not ensure true health protection. There are ongoing studies re-evaluating the role of VC in cancer treatment. Therefore, it would be also appropriate to reassess its use as a specific drug in the prevention and therapy of asthma, allergic rhinitis and atopic dermatitis.
\end{abstract}

Key words: vitamin C, deficiency, absorption, recommended dietary allowance, therapy.

\section{Introduction}

Until James Lind, an eighteenth century naval physician, recommended daily rations of lime or lemon juice to overcome ascorbic acid (AA) deficiency in the British Navy, thousands of sailors and voyagers had died during longdistance sea travels because of scurvy. Unfortunately, up to the beginning of the twentieth century there was no scientific proof that scurvy resulted from the lack of a specific nutrient and that it could be prevented or cured by appropriate dietary manipulation [1-3]. In 1928, Hungarian biochemist and Nobel Prize winner Albert Szent-Gyorgyi isolated and structurally characterised hexuronic acid. Four years later, in 1932, it was established that hexuronic acid and vitamin C (VC), a potent anti-scorbutic (Latin scorbutus, scurvy) factor were actually one and the same substance. A year later, Walter Norman Howarth synthesised crystalline AA, the most popular dietary nutriment throughout the world $[1,2,4]$.

\section{Vitamin C deficiency}

Vitamin $\mathrm{C}\left(\mathrm{C}_{6} \mathrm{H}_{8} \mathrm{O}_{6}\right.$; 2-oxo-L-threo-hexono-1,4-lactone2,3-enediol) commonly referred to as ascorbic acid (AA)) is a six-carbon lactone synthesised from glucose in the liver of most mammals, but not some birds, guinea pigs, bats, apes and humans. These species lack the enzyme L-gulono-1, 4-lactone oxidase catalysing the conversion of L-gulonolactone into AA. Thus, humans are completely dependent on AA from fresh fruits, vegetables or synthetic VC $[2,4,5]$.

Severe VC deficiency in human diet causes scurvy, a plague of ancient and medieval times. Low levels of AA in tissues and cells have been associated with anaemia, gingival bleeding, capillary haemorrhages, poor wound healing, atherosclerotic plaques, muscle degeneration or neurological disturbances [1, 3, 4]. Vitamin C deficiency lowers resistance to infections, inhibits the immune system, increases the risk of allergic sensitisation and negatively

Address for correspondence: Prof. Ryszard Rutkowski MD, PhD, 20 m. 6 Starobojarska St, 15-073 Bialystok, Poland, phone: 608255 565, e-mail: rutkowski@csk.pl 
influences the clinical course of many chronic diseases $[2-4,6]$. To prevent deficiency in pregnancy, lactation, smokers and the elderly as well as during inflammatory, degenerative and oncological diseases, synthetic AA in the form of (effervescent and chewable) tablets, capsules, crystalline powder or liquid may be necessary $[4,7,8]$.

\section{Sources of vitamin C}

Vitamin C as a water-soluble compound is readily available and easily absorbed but it is not stored in the body. Hence to maintain AA pool in the body, humans require VC in their diet. Citrus fruits, strawberries, raspberries, blueberries, cranberries, kiwi, mango, grapefruit, tomatoes, broccoli, Brussels sprouts, spinach, red and green peppers and other leafy vegetables (Table 1) are the major food sources of VC $[3,4]$. Human diet normally contains its two forms. Ascorbate or L-AA is the reduced compound. Dehydroacorbic acid (DHA) chemically defined as threo-2,3-hexodiulosonic acid- $\gamma$-lactone represents an oxidized form of VC. Ascorbate constitutes $80-90 \%$ of VC in the food; DHA in food varies from $10 \%$ to $20 \%$ of total VC [9-11].

\section{Vitamin C absorption}

When taken orally, plasma and tissue concentrations of VC are tightly controlled and strictly dependent on intestinal absorption, tissue accumulation and renal reabsorption [12].

In the gastrointestinal tract VC is absorbed via the buccal mucosa, stomach and small intestine. L-ascorbic acid is absorbed largely in the ileum and jejunum; oxidized DHA in the proximal intestine (duodenum and jejunum) Buccal absorption is mediated by passive diffusion. Gastrointestinal absorption occurs through active sodiumdependent, energy-requiring and carrier-mediated transport $[10,13]$. Dehydroacorbic acid enters epithelial cells through facilitated diffusion via sodium-independent glucose transporters. Then, on the internal side of the plasma membrane, DHA is rapidly recycled back to AA which prevents its efflux and allows the accumulation of ascorbate against a concentration gradient $[10,14,15]$. Ascorbic acid is readily absorbed from the intestine. The absorption of dietary VC is nearly complete and inversely related to the dose ingested. At higher intakes it reaches the saturation point relatively quickly. Hence, to achieve the maximal gastrointestinal absorption, several doses smaller than $1000 \mathrm{mg}$, spaced throughout the day, are better than a single large dose $[13,16]$. Vitamin C absorbed in the digestive tract circuits mainly as unbound $\mathrm{AA}$ and is available as an anti-oxidant in the blood and interstitial fluids [3]. Intracellularly it is reversibly oxidized to an ascorbic radical (semidehydroascorbic acid - SDA) which donates the second electron converting into dehydroacorbic acid or dismutates into ascorbate and DHA [17-19]. In the cytosol SDA is reduced back to ascorbate
Table 1. Ascorbic acid content in selected fruits and vegetables [5]

\begin{tabular}{|c|c|}
\hline Fruits & $\mathrm{mg} / 100 \mathrm{~g}$ edible portion \\
\hline Banana & $8-16$ \\
\hline Apple & $3-30$ \\
\hline Mango & $10-15$ \\
\hline Pineapple & $15-25$ \\
\hline Cherry & $15-30$ \\
\hline Papaya & 39 \\
\hline Orange & $30-50$ \\
\hline Grapefruit & $30-70$ \\
\hline Lemon & $40-50$ \\
\hline Strawberry & $40-70$ \\
\hline Currant black & $150-200$ \\
\hline Rose hips & $250-800$ \\
\hline Vegetables & $\mathrm{mg} / 100 \mathrm{~g}$ edible portion \\
\hline Onion & $10-15$ \\
\hline Tomato & $10-20$ \\
\hline Egg plant & $15-20$ \\
\hline Radish & 25 \\
\hline Spinach & $35-40$ \\
\hline Cabbage & $30-70$ \\
\hline Cauliflower & $50-70$ \\
\hline Broccoli & $80-90$ \\
\hline Coriander & 90 \\
\hline Brussels sprout & $100-120$ \\
\hline Pepper & $150-200$ \\
\hline Parsley & $200-300$ \\
\hline
\end{tabular}

by $\mathrm{NADH}$-dependent semidehydroascorbate reductase or NADPH-dependent thioredoxin reductase. Circulating DHA is rapidly transported into leukocytes, erythrocytes and many insulin-sensitive tissues via glucose transporters. In the cells DHA is reduced back to ascorbate by the gluthatione-dependent enzyme, glutaredoxin or thioredoxin reductase $[14,15,19,20]$. If not recycled to ascorbate DHA it is irreversibly hydrolyzed to 2,3-diketogulonic acid (DKG) which does not function as an antioxidant. In humans, 2, 3 DKG is further converted to oxalate and threonate. In plants and animals synthesizing VC, DKG may be metabolized to xylose, xylonic acid and lynxonic acid. Oxalate in humans is considered a true metabolic "end product" because there is no evidence that tissues utilize it any further $[4,14,19,21]$. 


\section{Body concentrations of vitamin C}

Vitamin C exists predominately in the blood and body in the reduced form. Compared with plasma VC, tissue levels are generally far higher. The highest concentration of VC is in leukocytes, adrenal and pituitary glands, skeletal muscles, brain, whereas low levels are found in serum, saliva and erythrocytes. Ascorbic acid is present in the blood at normal concentrations of 25-90 $\mu \mathrm{M} / \mathrm{l}$, whereas ascorbate concentration in the nucleated cells is typically millimolar. In circulating neutrophils AA concentration is at least 14 times higher than in plasma or erythrocytes. Human erythrocytes maintain intracellular ascorbate concentration equivalent to its plasma concentration [18, 22, 23]. Nearly $99.5 \%$ of extracellular VC consist of AA, whereas DHA is present only in very low concentrations $(<0.5 \%$ of total ascorbate in plasma) or not at all [24].

Within the narrow dose range of $30 \mathrm{mg}$ to $100 \mathrm{mg}$, a VC concentration increases substantially in both plasma and cells. At $<100 \mathrm{mg} /$ day there is a steep sigmoidal relationship between dose and concentrations. At a dose of $30 \mathrm{mg}$, nearly $90 \%$ of AA is absorbed, while at a dose greater than $1000 \mathrm{mg}$, less than 50\% is absorbed. At $100 \mathrm{mg}$ daily, a steady-state plasma concentration is about $60 \mu \mathrm{M} / \mathrm{l}$ for both genders. At $200 \mathrm{mg}$, usually achieved in humans with five servings of fruits and vegetables, plasma concentration is about $70 \mu \mathrm{M} / \mathrm{l}$. At doses of $400 \mathrm{mg}$ daily, the highest steady-state plasma concentration of approximately $80 \mu \mathrm{M} / \mathrm{l}$ is achieved [12, 15, 23]. At $500 \mathrm{mg} /$ daily and above, plasma concentrations do not increase because cellular transporters are completely saturated and exaggerated urine excretion of AA occurs. Urinary excretion does not occur below the $100 \mathrm{mg}$ /day dose [13, 15, 23].

\section{Cellular transport of vitamin C}

Ascorbic acid is ubiquitously distributed in human tissues and fluids. Its oxidized DHA form contributes generally less than $10 \%$. The flux of reduced and oxidized VC in and out of human cells is controlled by various mechanisms. Ascorbic acid crosses cell membranes against the electrochemical barrier with high-affinity, low-capacity sodium-dependent VC transporters (SVCT1, SVCT2) with a different tissue distribution $[19,25,26]$. Sodium-dependent VC transporter 1 is responsible mainly for intestinal absorption and renal reabsorption. Sodium-dependent VC transporter 1 carries VC across the intestinal barrier, while further VC transport from blood into the cells depends on SVTC2 transporters [26-28].

Sodium-dependent VC transporter 1 is referred to as the "bulk" transporter of L-AA and is involved in the wholebody homeostasis of VC. Sodium-dependent VC transporter 2 has been implicated in the maintenance of intracellular VC levels vital for the neuronal functions and protection against oxidative stress. Sodium-dependent VC transporter 2 has a higher affinity for AA, therefore it protects metabolically active cells (neurons, chondrocytes, keratinocytes) against oxidative stress [25-27, 29].
Gradient-driven transport of the oxidized, hexose-like dehydroascorbic acid is mediated by low-affinity, highcapacity sodium-independent glucose transporters particularly GLUT1, GLUT3 and GLUT4, with no affinity for AA and ascorbate [17, 25, 27]. In human erythrocytes the association of GLUT1 C-terminal peptide with stomatin, an integral erythrocyte membrane protein is responsible for the preferential uptake of DHA. Stomatin, a structural, cholesterol-binding protein is expressed at high levels with 100000 molecules per cell. The number of the facilitative GLUT1 exceeds 200000 molecules per cell [17, 18, 30].

Excess plasma or intracellular DHA is toxic and induces oxidative injury. To protect human cells, intracellular DHA is rapidly converted to AA by the dehydroascorbate reductase or irreversibly hydrolysed into 2,3-diketogulonic acid (DKG). Similarly, extracellular DHA is rapidly excreted or immediately hydrolyzed. Hence, only a protective, reduced form of VC is detected in plasma and intracellularly [27, 31].

Several mechanisms of AA efflux from various cells including enterocytes have been proposed but not yet firmly established. Volume-sensitive and $\mathrm{Ca}^{2+}$-dependent anion channels (VSOAC), gap-junction hemichannels, exocytosis of ascorbate-containing vesicles, glutamateascorbate hetero-exchange, ascorbate-ascorbate homoexchange may play a role. It appears that at least in certain cells ascorbate efflux occurs through anion channel-mediated diffusion. This is the most plausible of all proposed pathways for ascorbate efflux [17-19].

\section{Adverse effects of vitamin C}

In the kidney, AA is filtered from the glomerulal capillary bed into the Bowman's capsule and reabsorbed in the proximal convoluted tubules with the participation of SVCT1 transporters [4, 25, 29]. At $500 \mathrm{mg}$ and above daily dose, plasma concentration does not increase because VC cellular transporters are saturated and exaggerated urine excretion commences. The $500 \mathrm{mg}$ and $1250 \mathrm{mg}$ single doses of VC are entirely excreted in urine $[13,23]$. This mechanism explains its non-toxicity even in high doses. Potentially adverse effects do not occur $<1000 \mathrm{mg}$ and only above this daily dose urine uric acid and oxalate levels increase [23]. In prospective observational studies, there was no relationship between excessive AA and kidney stone formation, pro-oxidant effects or excess iron absorption [32, 33]. Ascorbic acid however is endogenously metabolized to oxalates which enhances the pool of oxalates in the human body. Oxalates are also excreted in urine if VC ingestion is excessive. Hence, in a genetically predisposed individual a high VC intake can increase the risk of calcium oxalate kidney stones [25, 34].

The tolerable upper limit for VC based on gastrointestinal symptoms is estimated at 2000 mg/day. A higher intake may trigger mild nausea, vomiting or osmotic diarrhoea. They are however easily reversed within a week or two of reduced intake $[2,3,35,36]$. Chronic administration of large doses of VC may also adversely affect body iron 
Table 2. Recommended dietary allowance (RDA) and tolerable upper limit (TUL) of vitamin C [33]

\begin{tabular}{llcc}
\hline & Age [years] & \multicolumn{1}{c}{$\begin{array}{c}\text { Vitamin C RDA } \\
\text { [mg/per day] }\end{array}$} & $\begin{array}{c}\text { Vitamin C TUL } \\
\text { [mg/per day] }\end{array}$ \\
\hline $1-3$ & & 15 & 400 \\
\hline $4-8$ & & 25 & 650 \\
\hline $9-13$ & Girls & 45 & 1200 \\
\cline { 2 - 4 } $14-18$ & Boys & 65 & 1800 \\
\hline 19 and older & Females & 75 & 2000 \\
\cline { 2 - 4 } & Males & 75 & 1800 \\
\hline Pregnant women & 18 and younger & 90 & 2000 \\
\cline { 2 - 4 } & 19 and older & 80 & 1800 \\
\hline Breastfeeding women & 18 and younger & 85 & 2000 \\
\cline { 2 - 4 } & 19 and older & 115 & 120 \\
\hline
\end{tabular}

reserve in hereditary hemochromatosis. In turn, patients with a glucose-6-phosphate dehydrogenase deficiency treated with high doses of intravenous VC are at risk of intravascular haemolysis [37, 38].

\section{Recommended daily allowance for vitamin C}

The US Food and Nutrition Board of the Institute of Medicine established the Dietary Reference Intake (DRI) values for the US population in 1941 [35]. It includes estimated average requirements (EAR), recommended dietary allowance (RDA) (average daily dietary intake level sufficient to meet the nutrient requirements of nearly all healthy individuals in a given group) and the tolerable upper intake level (TUL). Recommended dietary allowance and TUL for AA significantly depend on age and sex and increase in pregnancy, lactation, smokers and diseases associated with oxidative stress (Table 2) [32, 33]. Currently VC RDA requirements differ between countries with the highest value (110 mg/day) in France [2, 39]. In Poland, RDA is still 60-70 mg/day for both genders, whereas in the USA it is $75 \mathrm{mg} /$ day for women and $90 \mathrm{mg} /$ day for men. These RDA levels maintain a total body pool of AA of 1.2-2.0 g and physiological plasma concentrations of $40-80 \mu \mathrm{M} / \mathrm{l}[15,17,36,40,41]$.

\section{Is current RDA adequate?}

Modern farming methods have lowered VC levels in food. Humans consume cultivated plants with less VC than in wild variants $[42,43]$. Vitamin C is lost during storage and food processing. Light, oxygen exposure, oxidizing metals $\left(\mathrm{Cu}^{2+}, \mathrm{Ag}^{+}, \mathrm{Fe}^{3+}\right)$ or high temperature negatively influence its content in raw fruits and vegetables. Boiling, steaming, freezing, canning also diminish its stability and concentration in foods [3, 4]. Moreover, current RDA falls on the sigmoid part of the curve of VC pharmaco-kinetics, hence even small changes in intake produce large changes in plasma concentration. For this reason Levine et al. have claimed for many years that American RDA is too low in relation to real human needs and does not ensure true health protection. They postulate, based on current pharmacokinetic knowledge, that RDA for VC be re-evaluated and increased to a desirable daily dose of $200 \mathrm{mg}$ [23, 35, 39].

Additionally, numerous studies have demonstrated that VC consumption higher than current RDA enhances the immune system, protects against oxidative DNA damage, decreases the risk of certain cancers and chronic diseases $[2,13,35,36,44]$. Therefore, based on evidence-based literature, humans should consume more than five servings of fruits and vegetables daily, with a 1000 mg VC supplementation split in 2 or 3 doses, in order to ensure optimal levels of VC $[2,35]$.

There are ongoing studies re-evaluating the role of VC in cancer treatment. Therefore, it would be also appropriate to reassess its use as a specific drug in the prevention and therapy of asthma, allergic rhinitis and atopic dermatitis $[6,45]$. There are however a few caveats. It would be crucial to administer it intravenously to bypass the cellular and tissue mechanisms which tightly regulate its concentration when it is ingested orally. Moreover, these new therapeutic doses should be much higher than those used in previous studies, which have been found inconclusive in the recent Cochrane metanalysis $[45,46]$. Research on VC should be carried out rigorously in a double-blind, placebo-controlled fashion, in a large cohort of randomized patients and for a reasonably long period. Studies of high parenteral doses of VC in animal models of asthma and other allergic diseases are also desirable. Only methodologically robust research will form the basis for recognition of VC as an antiallergic and/or anti-oxidant drug reducing the mucosal and/or cutaneous inflammation. This would be an important step because of the widespread availability of VC in fruits and vegetables and lack of its toxic effects even in very high doses. 


\section{References}

1. Baron JH. Sailors' scurvy before and after James Lind a reassessment. Nut Rev 2009; 67: 315-32.

2. Basnet P. Vitamin C. Prevention of chronic diseases and clinical doses. NFT 2010; 9: 20-4.

3. Schlueter AK, Johnston CS. Vitamin C: overview and Update. JEBCAM 2011; 16: 49-57.

4. Naidu KA. Vitamin $C$ in human health and disease is still a mystery? An overview. Nutr J 2003; 2: 7-16.

5. Johnston CS, Steinberg FM, Rucker RB. Ascorbic acid. In: Handbook of vitamins. Zempleni J, Rucker RB, McCormick DB, Suttie JW (eds.). CRC Press, Boca Raton, FL, USA 2007; 489-520.

6. Allan K, Kelly FJ, Devereux G. Antioxidants and allergic disease: a case of too little or too much? Clin Exp Allergy 2010; 40: $370-80$

7. Wolańczyk-Medrala A, Barg W, Radlińska A, et al. Food-dependent exercise-induced anaphylaxis-sequence of causative factors might be reversed. Ann Agric Environ Med 2010; 17: 315-7.

8. Korzon-Burakowska A, Dziemidok P. Diabetic foot - the need for comprehensive multidisciplinary approach. Ann Agric Environ Med 2011; 18: 314-7.

9. Deutsch JC. Dehydroascorbic acid. J Chromatogr A 2000; 881 299-307.

10. Malo C, Wilson JX. Glucose modulates vitamin C transport in adult human small intestinal brush border membrane vesicles. J Nutr 2000; 130: 63-9.

11. Vanderslice JT, Higgs DJ. Vitamin C content of foods: sample variability. Am J Clin Nutr 1991; 54 (6 Suppl): 1323S-7S.

12. Levine M, Padayatty SJ, Espey MG. Vitamin C: a concentration-function approach yields pharmacology and therapeutic discoveries. Adv Nutr 2011; 2: 78-88

13. Iqbal K, Khan A, Khan Khattak MMA. Biological significance of ascorbic acid (Vitamin C) in human health - a review. Pak Nut 2004; 3: 5-13.

14. Bánhegyi G, Braun L, Csala M, et al. Ascorbate metabolism and its regulation in animals. Free Radic Biol Med 1997; 23 : 793-03.

15. Padayatty SJ, Levine M. New insights into the physiology and pharmacology of vitamin C. CMAJ 2001; 164: 353-5.

16. Basu TK, Donaldson D. Intestinal absorption in health and disease: micronutrients. Best Pract Res Clin Gastroenterol 2003; 17: 957-79.

17. Corti A, Casini AF, Pompella A. Cellular pathways for transport and efflux of ascorbate and dehydroascorbate. Arch Biochem Biophys 2010; 500: 107-15.

18. Lane DJ, Lawen A. Ascorbate and plasma membrane electron transport-enzymes vs efflux. Free Radic Biol Med 2009; 47: 485-95.

19. Linster CL, Van Schaftingen E. Vitamin C. Biosynthesis, recycling and degradation in mammals. FEBS J 2007; 274: 1-22.

20. May JM, Mendiratta S, Hill KE, et al. Reduction of dehydroascorbate to ascorbate by the selenoenzyme thioredoxin reductase. J Biol Chem 1997; 272: 22607-10.

21. Burns JJ. Introduction: overview of ascorbic acid metabolism. Ann NY Acad Sci 1975; 258: 5-6.

22. Evans RM, Currie L, Campbell A. The distribution of ascorbic acid between various cellular components of blood, in normal individuals, and its relation to the plasma concentration. Br J Nutr 198; 47: 473-82.

23. Levine M, Conry-Cantilena C, Wang Y, et al. Vitamin C pharmacokinetics in healthy volunteers: evidence for a recommended dietary allowance. Proc Natl Acad Sci USA 1996; 93: 3704-9.

24. Dhariwal KR, Hartzell WO, Levine M. Ascorbic acid and dehydroacorbic acid measurements in human plasma and serum. Am J Clin Nutr 1991; 54: 712-6.
25. Li Y, Schellhorn HE. New developments and novel therapeutic perspectives for vitamin C. J Nutr 2007; 137: 2171-84.

26. Savini I, Rossi A, Pierro C, et al. SVCT1 and SVCT2: key proteins for vitamin C uptake. Amino Acids 2008; 34: 347-55.

27. Fransson LA, Mani K. Novel aspects of Vitamin C: how important is glypican-1 recycling? Trends Mol Med 2007; 13: 143-9.

28. MacDonald L, Thumser AE, Sharp P. Decreased expression of the vitamin C transporter SVCT1 by AA in a human intestinal epithelial cell line. Br J Nutr 2002; 87: 97-100.

29. Takanaga H, Mackenzie B, Hediger MA. Sodium-dependent ascorbic acid transporter family SLC23. Pflugers Arch 2004; 447: 677-82.

30. Montel-Hagen A, Sitbon M, Taylor N. Erythroid glucose transporters. Curr Opin Hematol 2009; 16: 165-72.

31. De Tullio MC, Arrigoni O. Hopes, disillusions and more hopes from vitamin C. Cell Mol Life Sci 2004; 61: 209-19.

32. Carr AC, Frei B. Toward a new recommended dietary allowance for vitamin C based on antioxidant and health effects in humans. Am J Clin Nutr 1999; 69: 1086-107.

33. Food and Nutrition Board, VC. In: Dietary reference intakes for vitamin C, vitamin E, selenium, and carotenoids. A report of the Panel on Dietary Antioxidants and Related Compounds, Subcommittees on Upper Reference Levels of Nutrients and Interpretation and Uses of Dietary Reference Intakes, and the Standing Committee on the Scientific Evaluation of Dietary Reference Intakes. Institute of Medicine. Washington, DC: National Academy Press, 2000; 95-185.

34. Massey LK, Liebman M, Kynast-Gales SA. Ascorbate increases human oxaluria and kidney stone risk. J Nutr 2005; 135: 1673-7.

35. Deruelle F, Baron B. Vitamin C: is supplementation necessary for optimal health? J Altern Complement Med 2008; 14: 1291-8.

36. Ge M, O'Reilly A, Baille N, et al. Vitamin C: evidence, application and commentary. NZFP 2008; 35: 312-8.

37. Cook JD, Watson SS, Simpson KM, et al. The effect of high ascorbic acid supplementation on body iron stores. Blood 1984; 64: 721-6.

38. Rees DC, Kelsey H, Richards JD. Acute haemolysis induced by high dose ascorbic acid in glucose-6-phosphate dehydrogenase deficiency. BMJ 1993; 306: 841-2.

39. Levine $M$, Wang Y, Padayatty SJ, et al. A new recommended dietary allowance of vitamin C for healthy young women. Proc Natl Acad Sci USA 2001; 98: 9842-6.

40. Duda G, Saran A. Polish recommendations concerning vitamins and minerals consumer by elderly people. Farmacja Wspól 2008; 1: 16-23.

41. Leszczyńska T, Pysz M. Assessment of food consumption patterns of students of the faculty of food technology at the agricultural university in Cracow. Pol J Food Nutr Sci 2005; 14: 315 22.

42. Marler JB, Wallin JR. Human health, the nutritional quality of harvested food and suitable farming system. NSI White Paper. 2006, Nutrition Security Institute, Belleuve WA, US, www.nutritionsecurity.org

43. Milton K. Nutritional characteristics of wild primate foods: do the diets of our closest living relatives have lessons for us? Nutrition 1999; 15: 488-98.

44. Drisko JA, Chapman J, Hunter VJ. The use of antioxidant therapies during chemotherapy. Gynecol Oncol 2003; 88: 434-9.

45. Verrax J, Calderon PB. The controversial place of vitamin C in cancer treatment. Biochem Pharmacol 2008; 76: 1644-52.

46. Ram FS, Rowe BH, Kaur B. Vitamin C supplementation for asthma. Cochrane Database Syst Rev 2004; 3: CD000993. 